\title{
A Credibility-based Congestion Control Scheme and its Performance Evaluation*
}

\author{
Jin-xin Zhang, Man-gui Liang ${ }^{+}$ \\ Institute of Information Science, Beijing Jiaotong University \\ Beijing, 100044, China \\ E-mail: \{07112081,mgliang\}@bjtu.edu.cn \\ Shu-juan Wang \\ Columbia University, 1300 Seeley W. Mudd \\ New York,10027, USA \\ E-mail: shujuan@ee.columbia.edu \\ Received 20 November 2011 \\ Accepted 15 June 2012
}

\begin{abstract}
A congestion control scheme based on credibility is proposed. In this scheme, the whole $\mathrm{n}$ etwork is divided into several indepen dent domains, and e ach dom ain con tains a congestion control server (CCS) and several control modules (CM). The CCS is used to collect credit information and make punish ment decisions based on the credit information, while the $\mathrm{CM}$ cr eates signaling packets to calculate responsibility mark. Violators will be punished according to the ir responsibility mark. The effectiveness of this scheme is also analyzed. We provide simulation results to demonstrate that the proposed scheme can process congestion and provide better performance gains.
\end{abstract}

Keywords: congestion control; credibility-based; effectiveness; low cost

\section{Introduction}

Although computer networks have overspread largely in recent yea rs, it only provides si ngle class of " best effort" s ervice, th ere is no admission c ontrol and the network offers $n$ o a ssurance $a b$ out $w$ hen, or eve $n$ if, packets will be $d$ elivered [1]. Th e $\mathrm{m}$ ain reason is th at the simple design of Internet $m$ akes it a great success , but it also brings a lot of problems. Congestion is one of the most severe problems.

In ad dition, $n$ etwork secu rity is very im portant for its stab le o peration. Denial-of-Service (DoS) is on e of the $\mathrm{m}$ ost popular at tack fa shions. It $\mathrm{m}$ akes net work resource unavailable to its intended users, and ca uses congestion. Thu s, cong estion control ca $\mathrm{n}$ a lleviate the loss of DoS attack, but it can not avoid being attacked.

Generically, co ngestion contro 1 algo rithm can be modeled as a feedbac $\mathrm{k}$ sy stem where $\mathrm{t}$ he input is congestion information and the output is the adju stment sending rate of the end system; in turn, the sending rates of end systems affect the state of congestion $i \mathrm{n}$ the network [2].

Congestion can not be solved by simply in creasing network resource, for example, large buffer space, highspeed 1 inks and high-speed processors [3]. The desi gn objectives of congestion control algorithm contain: low overhead, fair, distributed and efficiency.

${ }^{*}$ This work was supported by Ministry of Science and Technology of China (Grant No 2007AA01Z203).

+ The corresponding author. 
In $\mathrm{t}$ his $\mathrm{p}$ aper, we propose a cred ibility-based congestion control scheme [4] and it works at $n$ etwork layer. For th is sch eme, o nly so urce is resp onsible for traffic shaping, other elements in network don't need to do th is work, so the cost of network is decreased. The whole network is di vided into se veral domains, so the risk among network is isolated effectively.

The remainder of this paper is organized as follows: section 2 in troduces the related works; in sectio $n 3$, the proposed sch eme is exp lained $\mathrm{i} n$ detail; th $\mathrm{e}$ effectiveness of the $\mathrm{p}$ roposed $\mathrm{sc}$ heme is explained i $\mathrm{n}$ section 4; numerical simulations are given in section 5; section 6 concludes this paper up.

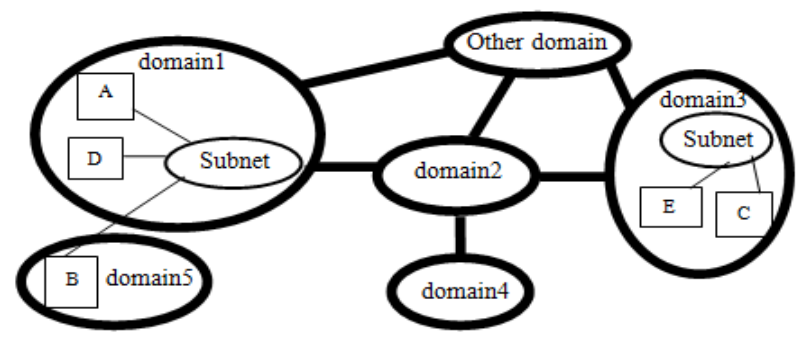

Fig. 1 Illustration of domain

\section{Related Works}

In the last few years, TCP congestion control policy has been ex tensively stu died in $t$ he literatures [5]-[9]. The primary methods re gulate the co ngestion window si ze maintained by each TCP se nder [5]. The com ing approaches $\mathrm{f}$ or network co ngestion co ntrol c over a broad range of techniques, including source quench [6], slow st art, sc hedule-based c ontrol [7], binary feed back [8] a nd rate -based c ontrol [ 9]. M oreover, Lo w [10] proposed an op timization fra mework $b$ ased on utility function, and $\mathrm{d}$ esigned a series of $\mathrm{n}$ ew co ngestion control schem es that can a chieve relative bala nce of objectives: using $\mathrm{n}$ etwork effectiv ely, allo cating resource fairly and low queuing delay.

The TCP $\mathrm{c}$ ongestion $\mathrm{c}$ ontrol an $\mathrm{d} t$ he $\mathrm{c}$ ongestion control sc heme based on o ptimization all work at the transport layer, so it $\mathrm{m}$ ay cause si gnificant $\mathrm{d}$ elay between congestion occurring and taking control action. If the leng th of info rmation sequence is very short, the feedback may be arrived after the s ource sent all data. Therefore, a cred ibility-based co ngestion co ntrol scheme i s pr oposed i $\mathrm{n} t$ his pa per. It $\mathrm{w}$ orks at $\mathrm{t}$ he network layer, and can take control action immediately. The a dvantages of this sc heme cont ain: $d$ on't nee $d$ to allocate resource at network layer, only increase $t$ he complexity of the s hared resource (switch, etc.); ca $n$ decrease the cost of whole network.

The proposed sch eme is similar to co mputational intelligence, an $\mathrm{d}$ it is self-ad aptive. In $\mathrm{t}$ he $\mathrm{b}$ eginning, there are a number of violators. When violator realizes the serous punishment, it will restrict its $b$ ehavior. The most serio us violator will be prohibited fro $\mathrm{m} \mathrm{u}$ sing network. Finally, there are only several violators so that the entire network will be more safe and reliable.

\section{Credibility-based Congestion Control Scheme}

\subsection{Definition}

Domains are usu ally divided into several subnets in the light of regions or ot her purposes. Fi g. 1 shows a network example. The thick circles denote subnets, and it co ntains smaller su bnet (th in circles) o $r$ term inal nodes (rectangles).

We define a $\mathrm{d}$ omain as a $\mathrm{s}$ ubnet which has congestion co ntrol schemes and runs independently. A domain consists of one congestion control server (CCS) and several port controllers (PC). CCS is responsible for storing and collecting ge neral information, PCs control communication with ot her parts in network. The basic idea is t o c ompute each CCS's responsibility mark according to congestion state, and then use thi $\mathrm{s}$ information to give punishment to CCS related domains. The en tire network's respo nsibility is $\mathrm{p}$ roviding each node's responsibility mark to the decision center, so that the punishment can be decided.

\subsection{Congestion Control Model}

The congestion control model is sh own in Fig . 2. Data are sen $t$ fro $\mathrm{m}$ rig ht to left. Th e righ t irreg ular circle denotes the source subnet, the left one is the destination subnet, and the middle ci rcle is the domain named A where congestion occurs. A connected with source and destination su bnets $t$ hrough ports which in clude congestion control modules (CM). We call the entrance module in port con nects source subnet and A as InM, and the outlet module in port connects $\mathrm{A}$ and destination subnet as OutM. S and D is source and destination, the diamond shows congestion point. 


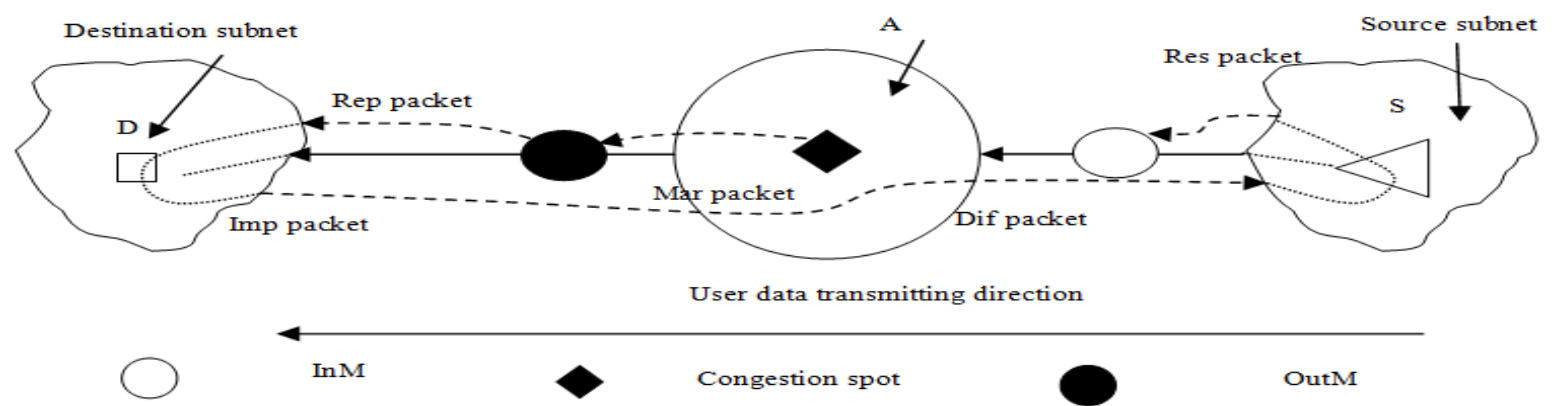

Fig. 2. Congestion control model.

The congestion control process will create five kinds of si gnaling packets: $\mathrm{M}$ ar packet, Re p packet, Imp packet, Dif packet and Res packet. Their specifications are given as follows:

- Mar p acket: $\mathrm{w}$ hen congestio $\mathrm{nh}$ appens, th e corresponding switching equipment samples some data packets, and changes these data packets into Mar packets by altering the data packets' header.

- Rep packet: OutMs create Rep packets base on the number of $\mathrm{M}$ ar packets, and recover Mar packets into data packets.

- Imp packet: destinations c reate Im p pac kets to inform sources that congestion happens.

- Dif pac ket: InMs cha nge Im p packets into Dif packets to inform sources the congestion.

- Res packet: sources ' res ponses after recei ved Dif packets, carry acknowledg ement or clarification information.

- Acknowledgement i nformation: s ources adm it violation aft er sel f-check, a nd acc ount for taking responsibility.

- Clarification in formation: s ources declare innocence.

We suppose the diamond rectangle is the congestion spot (nam ed as G). G se nds Ma r p ackets to Ou tM. OutM then creates Rep packets, rev erting Mar p ackets into data packets, and send $\mathrm{s} t$ hem to the $\mathrm{d}$ estination subnet. After receives $\mathrm{R}$ ep packets, sources are informed that congestion happens in the routes, $\mathrm{t}$ hen sources se nd back Im p packets t o OutM. OutM forwards Imp packets into network, and there will be 3 results for the packets:

(i) Reach at the right source;

(ii) Reach at wrong sources;

(iii) Don't reach any source or end equipment.

Source will send b ack packets carrying acknowledgement or clarification information in case (i). In case (ii) o $\quad r$ (iii), end eq uipments o $r$ related intermediate e quipments will sen $\mathrm{d}$ m essages to alar $\mathrm{m}$ the system that network failure occurs and InM w on't get Res packets. The coun ters will be tri ggered when signaling $\mathrm{p}$ asses thr ough OutM an d InM, as Fi g. 3 shows.

Counter variables specifications are given as follows:

- Crep: count fo $\mathrm{r}$ re port, stores in O utM, po rt granularity.

- Cim: count for impeachment, stores in OutM, port granularity.

- Cdi: count for diffuse impeachment, stores in InM, aggregation paths granularity.

- Cac: count for acknowle dgement, stores in InM, aggregation paths granularity.

- Ccl: count for $\mathrm{cl}$ arification, st ores i $\mathrm{n} \mathrm{InM} \mathrm{,}$ aggregation paths granularity.

Take all $\mathrm{p}$ aths from InM to OutM in domain as on e aggregation path, we can compute three sampling values, Sl for not-im peach sam pling, $S r$ for not -response sampling, and $S a$ for acknowledgement sampling.

In dom ain's views, $\mathrm{c}$ ongestion CMs are $\mathrm{t}$ he

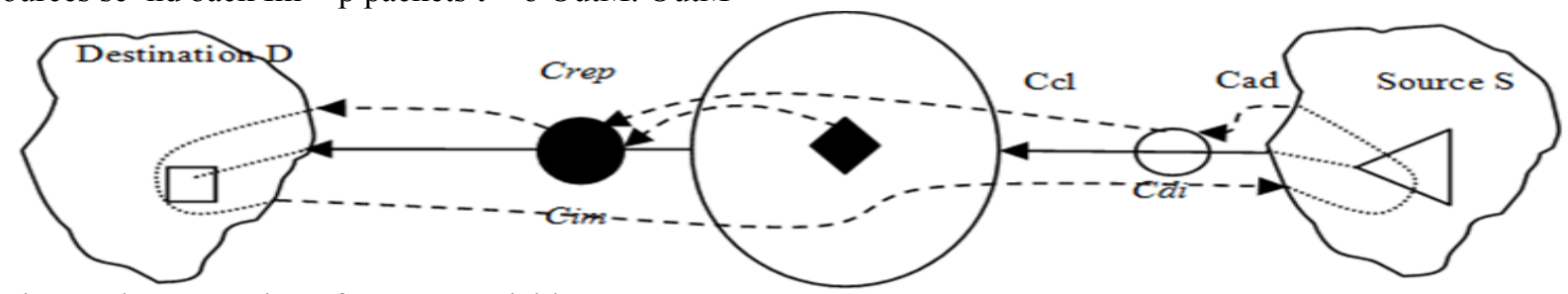

Fig. 3. The generation of counter variables. 
responsibility holders. Numbering the con gestion CMs, we can get the serial numbers of aggregation paths. For example, ift here a re $\mathrm{N}$ m odules on the edge of $\mathrm{t}$ he domain, numbered by $\{1,2, \ldots, N\}$, the ag gregation path from $\mathrm{i}$ to $\mathrm{j}$ mark ed as $[i, j]$, where $\mathrm{i}$ is InM's number and $\mathrm{j}$ is OutM's number. All parameters in OutM form a one-dimension array with subscript $[j]$; all $\mathrm{p}$ arameters in InM form a two-dimension array with subscript $[i, j]$. Responsibility $\mathrm{m}$ ark is co mputed as fo llows: once a counting time ( $\mathrm{p}$ re-defined) fi nished, $\mathrm{Ou}$ tM use Crep $[j]$ and $\operatorname{Cim}[j]$ to get $S I[j]$, InM use $C d i[i, j]$, $\operatorname{Ccl}[i, j]$ and $\operatorname{Cac}[i, j]$ to get $S a[i, j]$ and $\operatorname{Sr}[i, j]$ respectively, the values are computed by the following formulas:

(a) Not-im peach sampling $S I[j]$ : if destination can be $\mathrm{t} \quad$ rusted, $\mathrm{t}$ hen $\operatorname{Crep}[j]=\operatorname{Cim}[j]$. Otherwise $\operatorname{Crep}[j]>\operatorname{Cim}[j]$; Crep $[j]<\operatorname{Cim}[j]$ means that terrible problems occur and congestion CMs should alarm the system. Number j module's not-impeach mark:

$$
S I[j]=\frac{\operatorname{Crep}[j]-\operatorname{Cim}[j]}{\operatorname{Crep}[j]}
$$

If Crep $[j]=0, \operatorname{set} S I[j]=0$.

(b) Not-response sampling $\operatorname{Sr}[i, j]$ : if source can be trusted, then $\operatorname{Cdi}[i, j]=\operatorname{Ccl}[i, j]+\operatorname{Cac}[i, j]$ Otherwise $\quad \operatorname{Cdi}[i, j]>\operatorname{Ccl}[i, j]+\operatorname{Cac}[i, j]$ $\operatorname{Cdi}[i, j]<\operatorname{Ccl}[i, j]+\operatorname{Cac}[i, j] \quad$ means that terrible problems occur an $\mathrm{d}$ c ongestion $\mathrm{CMs}$ shoul $\mathrm{d}$ alarm the system. Aggregation path $[i, j]$ 's not response mark:

$$
\operatorname{Sr}[i, j]=\frac{\operatorname{Cdi}[i, j]-(\operatorname{Ccl}[i, j]+\operatorname{Cad}[i, j])}{\operatorname{Cdi}[i, j]}
$$

If $C d i[i, j]=0$, set $\operatorname{Sr}[i, j]=0$.

(c) Ac knowledgement sampling $S a[i, j]:$ a s ource needs to ta ke on som e responsibility whe $n$ it acknowledges violation. The calculating principle is that in one $\mathrm{c}$ ounting tim $\mathrm{e}$, if one $\mathrm{c}$ ongestion $\mathrm{CM}$ acknowledges vi olation, other $\mathrm{m}$ odules can a void punishment, only the o ne acknowledges be sc ored. Situation may exits that sev eral modules acknowledge violation, and th en all $\mathrm{m}$ odules would be scor ed one mark. In all above situations, $\sum_{i} \sum_{j} \operatorname{Cad}[i, j] \neq 0$.

If $\operatorname{Cad}[i, j]>0, S a[i, j]=1$; otherwise $S a[i, j]=0$.

All m odules' $\operatorname{Cad}[i, j]$ in the sam e d omain sh ould be take $\mathrm{n}$ int $\mathrm{o}$ account $\mathrm{t}$ o determine each $\mathrm{m}$ odule's $S a[i, j]$. After se veral counting tim es, all $\operatorname{Cad}[i, j]$ will be se nt to CCS t o be computed. If no congestion $\mathrm{CM}$ ackn owledges vi olation, which $\mathrm{m}$ akes $\sum_{i} \sum_{j} \operatorname{Cad}[i, j]=0$. Set $\Delta=\sum_{i} \sum_{j} \operatorname{Cd}[i, j]$, if $\Delta=0$, then $S a[i, j]=0$.

We set a period of time to im plement this m ethod. Take $R$ as an obj ect's responsibility mark in one counting time, which concerns the whole network effect. The $t$ otal sc ore in the set pe riod of ti me can be calculated as follows:

$$
U[n]=\lambda U[n-1]+(1-\lambda) R[n]
$$

$U[n]$ is the total score after $n$ counting times, $R[n]$ is the responsibility $\mathrm{m}$ ark i ncluding other m odules' e ffect in counting tim e $[n], 0 \leq \lambda \leq 1, \lambda=1 / M$, w here $M$ is the equivalent time length of counting times. Similarly, we can get formulas for $U l, U a$ and $U r$ as follows:

$$
\begin{aligned}
& U l[n]=\lambda U l[n-1]+(1-\lambda) R l[n] \\
& U a[n]=\lambda U a[n-1]+(1-\lambda) \operatorname{Ra}[n] \\
& U r[n]=\lambda U r[n-1]+(1-\lambda) \operatorname{Rr}[n]
\end{aligned}
$$

$R l[n], \operatorname{Ra}[n]$ and $\operatorname{Rr}[n]$ is left-responsibility mark, acknowledgement score and right-responsibility mark in number n c ounting tim e. $U l[n], U a[n]$ and $U r[n]$ is left-total score, ack-total score and right-total score after n counting ti mes. Sources are responsible for $U a$ and $U r$ in InM, a nd destinations a re responsible for $U l$ in OutM. $U l, U r$ and $U a$ are computed in each congestion $\mathrm{CM}$, and be sent to the CCS after a given period of time to get the quantification punishment.

\section{Effectiveness of Credibility-based Congestion Control Scheme}

Credibility means that all nodes are well-reputed except violators. Thus, acc ording to the $n$ umber of violators and the re putation of vi olators, the congestion ca $\mathrm{n}$ be divided into five cases in a domain.

\subsection{Single domain}
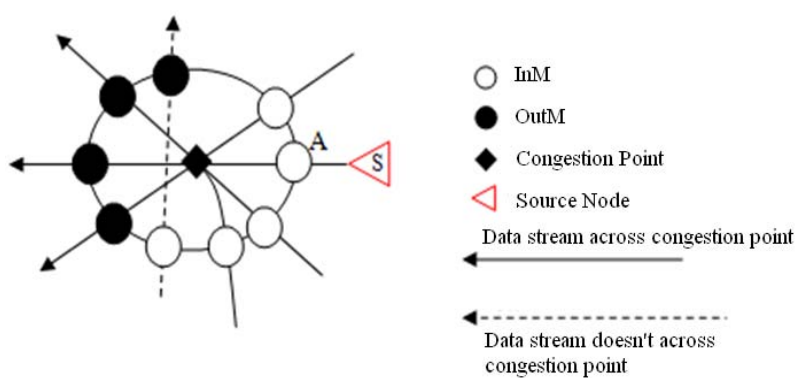

Fig. 4. The violation of a trustful source node in a domain.

(i) The violation of one trustful source node

As shown in Fig. 4, there is a trustful source node $\mathrm{S}$ violating the rules, which causes congestion in a domain, 
so c ongestion co ntrol sc heme is triggered. After receiving a Dif packet belongs to $\mathrm{S}$, it sends back a Res packet which carries ac knowledgement inform ation to InM A, and accounts for taking responsibility. The punishment result is that the violator $\mathrm{S}$ and its connected InM A have direct ackn owledgement marks, but other CMs don't have marks.

(ii) The violation of one distrustful source node

As s hown in Fig. 5, s uppose the s ource node $\mathrm{S}_{2}$ violates $\mathrm{t}$ he $\mathrm{r}$ ules, which causes $\mathrm{c}$ ongestion, so congestion control schem e is triggered. Then all InMs (A、B、C and D) se nd Dif packet to $t$ heir sources i $n$ the domain respectively. After receiving the Dif packet, these sources send back Res packets. Res packet contains tw o kinds of in formation: ack nowledgement information and clarification information.

In this case, source nodes $\mathrm{S}_{1} 、 \mathrm{~S}_{3}$ and $\mathrm{S}_{4}$ will send back Res pac kets carrying ac knowledgement information, because none of them violates the rules. As the so urce node $\mathrm{S}_{2}$ is the vi olator a nd is distrustful, it will also send bac $\mathrm{k}$ Res pac ket carrying acknowledgement inf ormation in order to av oid responsibility. All source nodes send back Res packets carrying acknowledgement information, so the CCS can not ide ntify w hich one is $t$ he violato $r$. T herefore, that congestion should be in charge of responsi bility by all four In Ms (A 、 B 、 C a nd D) on average . T heir responsibility marks are calculated based on their traffic level. The InM forwarding heavy traffic will undertake main responsibility, because the heavy tra ffic has hi gh possibility causing congestion.
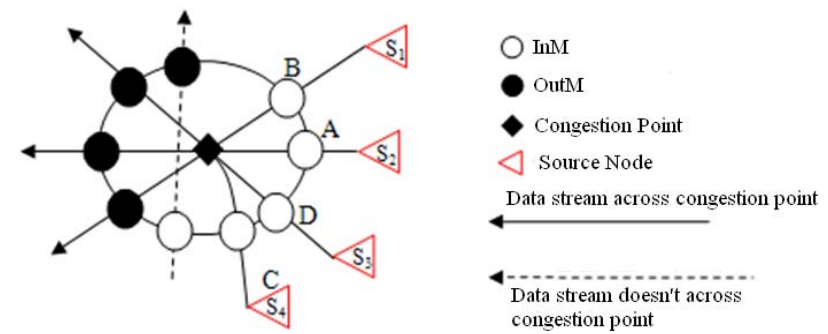

Fig. 5. The violation of a distrustful source node in a domain.

There are tw o m ethods to i dentify the violator. 1) when CCS receiving alar $\mathrm{m}$, it starts $\mathrm{m}$ onitoring equipment which is an arbitra tion equipment to identify the violator; 2) if there is no monitoring equipment, the innocent nodes may tolerant until reach their threshold. Then the innocent nodes may install m easuring module that will incurring som e costs. Finally, all node s install measuring modules except the violator, so it is easy to identify the violator in that case.

After identified violator, it will be punished hea vily and be set lo $\mathrm{w}$ repute lev el. Th e punish ment i $\mathrm{s}$ calculated by ti me interval from the beginning of congestion $\mathrm{t}$ o ide ntifying violator $\mathrm{m}$ ultiply the maximum cost per time.

(iii) The violation of multiple trustful source nodes

As shown in Fig. 5, suppose the source nodes $S_{1}$ and $\mathrm{S}_{2}$ violate the rules ca using congestion but the source nodes $\mathrm{S}_{3}$ and $\mathrm{S}_{4}$ do not violate the rules, so congestion control sc heme is $t$ riggered. A s all so urce $n$ odes are well-reputed, $S_{1}$ and $S_{2}$ will send bac k Res packets carrying ac knowledgement inf ormation to $\mathrm{A}$ a nd B respectively; $\mathrm{S}_{3}$ and $\mathrm{S}_{4}$ wi 11 send back Res packets carrying cla rification inform ation. $\mathrm{T}$ heir responsibility marks are undertaken by $S_{1}, S_{2}, A$ and $B$, and the mark of other InMs and source nodes will not be reduced.

(iv) The violation of multiple source nodes and only one distrustful source node

Suppose $\mathrm{m}$ ultiple source nodes violate the rules causing congestion but only one distrustful source node. In that case, the violator may not be punished, but it will generate heavy traffic again violating the rules owing to the fluke mind. Therefore, the violator will be identified sooner or later according to the case (ii).

(v) The violation of multiple distrustful source nodes

Suppose $\mathrm{m}$ ultiple source nodes violate the rules causing co ngestion an d none of them is trust ful node. That case is si milar to the ca se (iv), so the violator will be identified ultimately according to the case (ii).

\subsection{Multiple domains}

(i) The violation of one trustful source node

As shown in Fig. 6, there is a trustful source node $S_{1}$ communicating with destination $\mathrm{D}$, but it violates the rules that ca using several congestion points in m ultiple domains, so c ongestion c ontrol schem e is trigge red. Then all InMs located at the same domain as congestion points will identify the violator. As $S_{1}$ is well-reputed, it will send back Res pac ket carrying ac knowledgement information to its InM, and $\mathrm{S}_{2}$ will send back Res packet carrying clarification info rmation. $\mathrm{T}$ he responsibility mark is only undertaken by $\mathrm{S}_{1}$, and it is calculated by the number of congestion points.

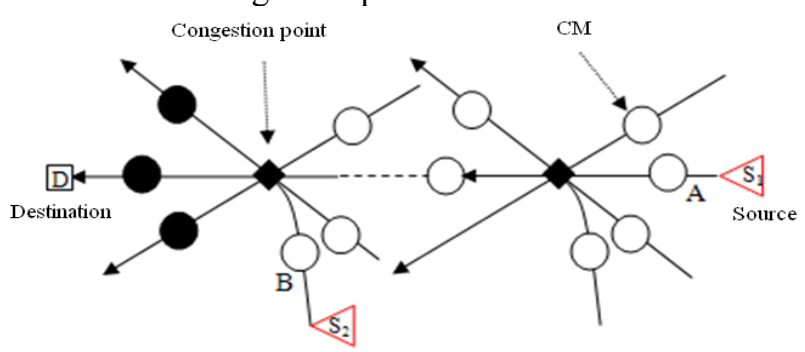

Fig. 6. The violation of a trustful source node in multiple domains.

(ii) The violation of one distrustful source node 
Suppose there is a trustful source violating the rules, which causes $\mathrm{n}$ congestion points in $\mathrm{m}$ ultiple domains, so $n^{*} \mathrm{x}$ node will be treate $\mathrm{d}$ unjustly, where $\mathrm{x}$ is the number of traffic ac ross congestion points. $T$ heir responsibility mark y is scaled by the sampling value of Cac. Therefore, the acknowledge responsibility mark of the violator is $\mathrm{n}^{*} \mathrm{y}$.

(iii) The violation of multiple trustful source nodes

Suppose m ultiple tr ustful s ource nodes vi olate the rules. A s all source nodes are inter-independent, the interferences among them are very low. Therefore, that case is similar to the case (i).

(iv) The violation of multiple source nodes and only one distrustful source node

Suppose m ultiple tr ustful s ource nodes vi olate the rules and only one distrustful source node. As all source nodes are inte r-independent, the interfere nces am ong them are very low. T herefore, that case is sim ilar to the case (ii).

(v) The violation of multiple distrustful source nodes

Suppose multiple distrustful source nodes violate the rules. A s all source nodes are inter-independent, the interferences among them are very low. Therefore, that case is similar to the case (ii).

\section{Numerical Simulations}

According to the effective ness the ory of cre dibilitybased congestion control scheme in section 4 , we only need to consider the case having one violator which is enough to vali date the feasi bility and effe ctiveness of the proposed congestion control scheme.

\subsection{Simulation topology}

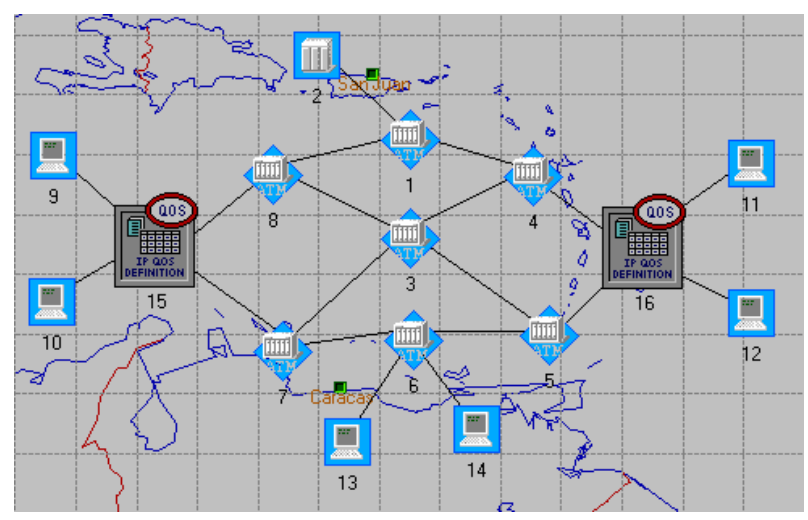

Fig. 7. The simulation network topology.

The sim ulation network topology is s hown in Fig. 7. Node 11 and 12 are s ource nodes, node 9 and 10 a re destinations, node 16 is In M, node 15 is Ou tM, node 2 is router which collects link inform ation and calculate path for term inal nodes. Suppose node 11 will send packets to node 10 , and node 12 will send packets to node 9 .

To compare the proposed congestion control scheme with c ommon netw ork, we also run sim ulation in the comparison topology which substitutes InM and OutM by ordinary switch nodes.

\subsection{Establishment of node model}

There are four kin ds o f no de models in the netw ork including: term inal node, switch node, InM/OutM a nd router. The terminal node is used to generate traffic and receive traffic and it does not nee $d$ to modify. The router refers to $r$ outing al gorithm and so me signalin $g$ protocols, so it is o ut of our consideration. Thus, only InM/OutM and switch node model need to de sign and implement in OPNET [11].

In or der to coordinate with the proposed schem e, only the queue module within switch node needs to be modified. The main functions of $\mathrm{q}$ ueue $\mathrm{m}$ odule are: cache packets and schedule.

The processing flowchart of queue is very important for the proposed congestion scheme. As shown in Fig. 8, when the lengths of queue reach $50 \%$, the low priority packet $\mathrm{m}$ ay be dropped $\mathrm{t} \mathrm{o}$ guarantee the s uccess transmission of high priority packet.

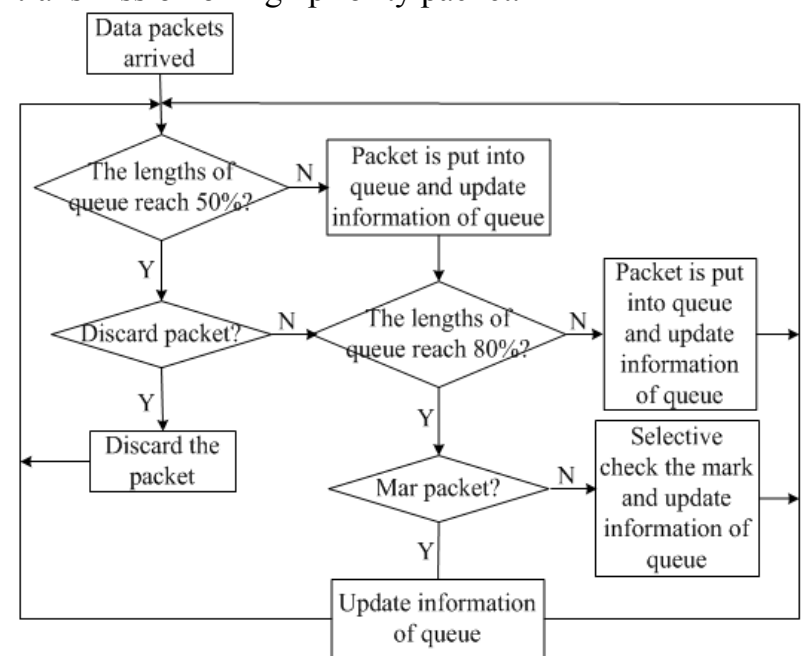

Fig. 8. The flowchart of queue module.

The InM/OutM node locate $d$ at the edge of domain and edge of domain is implemented by switch node, so the I nM/OutM n ode m odel should be a s witch node model. Their di fference is that $\mathrm{t}$ he $\mathrm{C} \mathrm{M}$ should be plugged i nto the InM/OutM. The flowchart of $\mathrm{C} \mathrm{M}$ is shown in Fig. 9.

\subsection{Validation of the proposed scheme}

In the case that violation of one source node, we set node 12 is the violator, which means that node 12 uses 
more bandwidth than it applied for, and then generate a congestion point at node 3 .

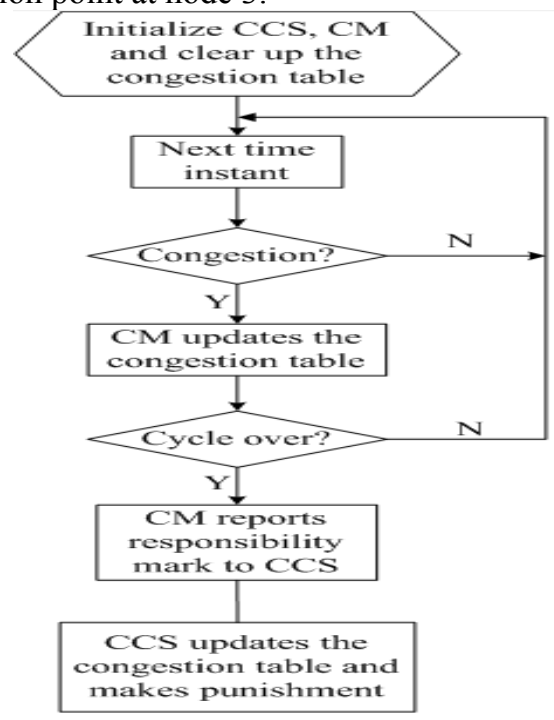

Fig. 9. The flowchart of congestion controller and congestion control server.

The parameter values use $d$ in the simulation are set as follows. The simulation time is set to $150 \mathrm{~s}$. The node 11 and 12 start sending packet at time 100s. The queue capacity of node 3 is set to 9600 bit. If the size of packets sent from node is $1024 \mathrm{bit}$, that is not a violation; if the node send packet with size of 4096bit or above, it will violate the rules. The working period of InM/OutM is set to $150 \mathrm{~s}$.

After running th e pr oposed cong estion co ntrol scheme, if InM/OutM can iden tify the violator 12 , that can prove the proposed scheme is feasible.

The neighbor relationships of OutM 15 and InM 16 are given below. In outM 15, node 9、 node 10、 node 8 and node 7 are connected by port 1 、 port 2 , port 3 and port 4 respectively. In In M 16, node 4 、 node 5 、 node 11 and node 12 are connected by port 1 , port 2 , port 3 and port 4 respectively.

The simulation results of OutM 15 and InM 16 are shown in Fig. 10 and Fig. 11 respectively.

\begin{tabular}{|c|c|c|c|c|}
\hline Erep & $\begin{array}{c}\text { porte-1 } \\
19\end{array}$ & $\begin{array}{c}\text { portz } \\
7\end{array}$ & $\begin{array}{c}\text { porta } \\
0\end{array}$ & port $^{4}$ \\
\hline Cc1 & 5 & G & 5 & 5 \\
\hline Eac & 5 & 5 & G & 5 \\
\hline Eim & 15 & 7 & G & 5 \\
\hline Edi & 5 & 5 & C & 5 \\
\hline
\end{tabular}

Fig. 10. The simulation result of node 15 .

As shown in Fig. 10, it is seen that only column port 1 and p ort 2 have non-zero value, beca use terminal nodes are connected by port 1 and port 2 . The OutM 15 received 10 a nd 7 Cre $\mathrm{p}$ pa ckets from node 9 a nd 10 respectively, a nd also recei ved 10 and 7 Cim packets from node 9 and 10 res pectively. The reason is: $w$ hen congestion happen at node 3, the OutM 15 se nds R ep packets based on Mar packet which created by node 3 to terminal no de 9 and 10 re spectively. The n node 9 and 10 send Imp packets to InM 16. After InM 16 received Imp packets, it sends Dif packets to source node 11 and 12 respectively. Finally, the source node 11 and 12 send Res packets to OutM 15.

$\begin{array}{lcccc} & \text { port1 } & \text { port2 } & \text { port3 } & \text { port4 } \\ \text { Co1 } & 5 & 5 & 17 & 0 \\ \text { Cac } & 5 & 5 & 5 & 17 \\ \text { Cim } & 5 & 5 & 0 & 0 \\ \text { Cdi } & 5 & 1 & 17 & 17\end{array}$

Fig. 11. The simulation result of node 16

As shown in Fig. 11, it can be seen that only column port 3 and port 4 have non-zero value, bec ause source nodes are connected by port 3 and port 4 . The InM 16 received $17 \mathrm{Ccl}$ and $17 \mathrm{Cdi}$ packets from node 11 , and received 17 Cac and $\mathrm{C}$ di packets from node 12 . Apparently, node 11 does not violate rules because InM received cla rification i nformation from node 11 , but node 12 violates rules causing congestion because InM received acknowledgement information from node 12 . It can be concluded that the proposed c redibility-based congestion control sc heme can i dentify the violators accurately.

\subsection{Performance Evaluation}

The performance of net work is $\mathrm{m}$ ainly describe $\mathrm{d}$ by packet drop ratio, $\mathrm{t}$ hroughput, tra nsmission delay, transmission jitter, and so on. In $\mathrm{t}$ his sim ulation, throughput and e nd-to-end delay are used to illustrate the effect of the proposed c ongestion cont rol scheme comparing to the case of without congestion control.

The parameter values use $d$ in the simulation are set as follows. The simulation end time is set to $150 \mathrm{~s}$. The node 11 and 12 start sen ding pac ket at time 10s. The queue ca pacity of switch nodes is set to 750 bit. The length of data packet is set to $30 \mathrm{bit}$. T he packet interarrival tim e subjects $t$ o Poisson distribution, a nd its mean value is set to $1 \mathrm{~s}$.

(i) Throughput

Network throughput is the average rate of successful packet d elivery ov er a lin k. Fig. 12 shows th e comparison re sults of throughput under th e case of having co ngestion $\mathrm{c}$ ontrol an $\mathrm{d}$ with out co ngestion control. I n t his sim ulation, data packets are se nt according $t \mathrm{o}$ Poisson distri bution, which $\mathrm{m}$ eans that traffic is added with time elapsing.

It is seen that throughput is inc reased with traffic increasing, but when tra ffic reac $h$ at som e value, throughput reach its $\mathrm{m}$ aximum value. If a dditional packets a re se nt to net work continually, throughput is 
not increased because of $c$ ongestion. The threshold of queue length is set ahead. When processing time larger than packet i nter-arrival tim e, som e packets $m$ ay be dropped due $t$ o the que ue reaching its li mit. Thus, on account of li mit of queue le ngth, when there is heavy traffic on network, throughput tends to b alance, but not decreases sharply.

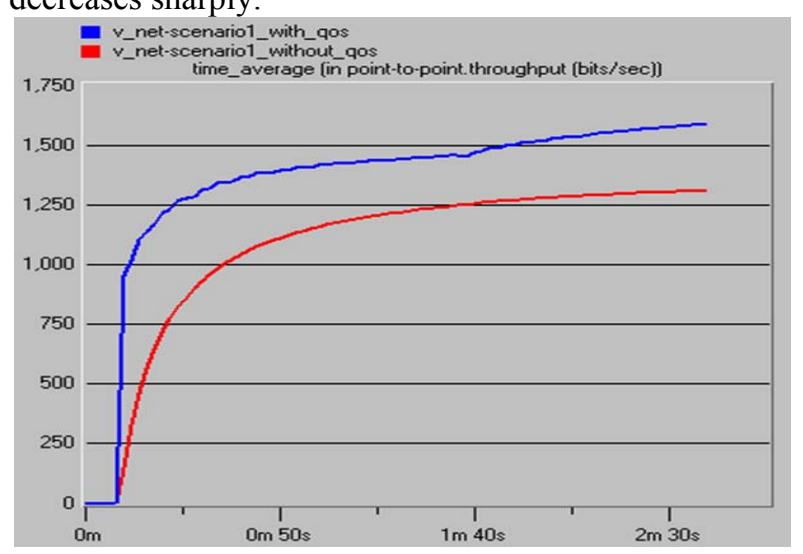

Fig. 12. The comparison result of throughput

Under the condition of light tr affic, thr oughput of network with and without congestion control sc heme is almost sam e. Ho wever, th e thr oughput of network without congestion control scheme keeps at lower value than congestion control scheme when the same traffic is employed. The reason is that many packets are dropped due t o c ongestion $\mathrm{w}$ hich ca uses lo $\mathrm{w}$ throughput, but congestion con trol sch eme can avo id co ngestion to some extent.

\section{(ii) End-to-end delay}

End-to-end de lay refers to the tim e take $\mathrm{n}$ for $\mathrm{a}$ packet to be transmitted across a network form source to destination. Fi g. 13 shows the comparison results of end-to-end delay with and without congestion control.

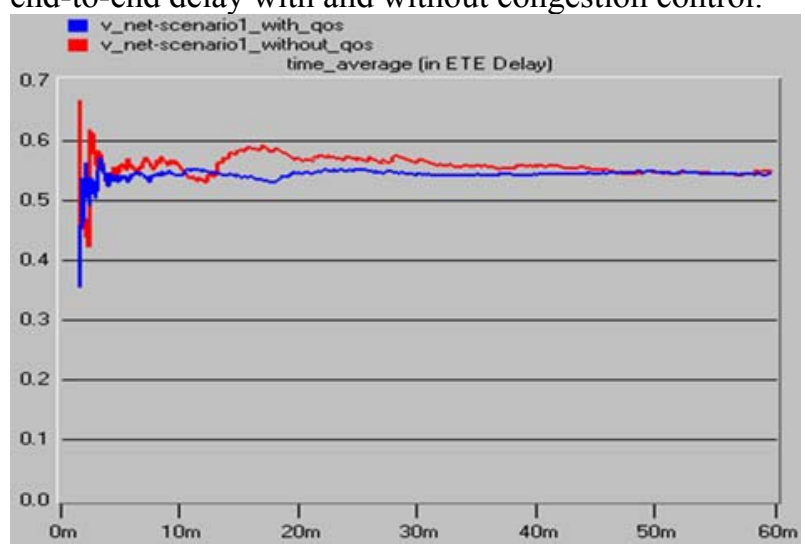

Fig. 13. The comparison result of the end-to-end delay

It is seen that end-to-end delays both tend to balance after jitter pe riod under $\mathrm{t}$ he $\mathrm{t}$ wo cases. The end-to-e nd delay eq uals about $0.55 \mathrm{~s}$ under $\mathrm{t}$ he ca se of without congestion control, whereas that value is about $0.54 \mathrm{~s}$ with congestion control.

In ge neral, end-to-end delay is com posed of transmission delay, propagation delay and queue delay. It is defined as follows.

$$
d_{\text {end-end }}=N \cdot\left(d_{\text {trans }}+d_{\text {prop }}+d_{\text {que }}\right)
$$

where $\mathrm{N}$ is the number of links.

In our simulation, since the distances between nodes are close a nd bandwidth of link is $1 \mathrm{Gbps}$, transmission delay and propagation delay can be omitted. Equation (7) can be simplified to

$$
d_{\text {end-end }} \approx N \cdot d_{\text {que }}
$$

Therefore, the $\mathrm{n}$ umber of 1 inks $\mathrm{f}$ rom source $\mathrm{t} o$ destination can be obtained by equation (8). The number of links with congestion control equals $0.54 / 0.09=6$, and it can be validated from Fig. 7.

Through a bove sim ulations, the proposed credibility-based c ongestion co ntrol sche me is proved that it can work accurate ly. The pe rformance of throughput and delay can be improved by the proposed scheme.

\section{Conclusion}

This pa per proposed a c redibility-based congestion control m ethod at netw ork layer. It divi ded the w hole network i nto seve ral domains, $t$ hus fa cilitated the question. It relied on sources' sel f-restrict to a void congestion, traffic shaping is only needed to be done in ports and great resources would be saved. By collecting and computing responsibility mark of each element, the congestion c ontrol se rver wo uld $\mathrm{m}$ ake decisio ns according to the $\mathrm{m} \quad$ ark, and $\mathrm{m}$ ade appropriate punishment to violato rs. Moreover, the effectiveness of this schem e is analy zed. We p rovided exte nsive simulation results to demonstrate $t$ hat $t$ he proposed scheme can process $\mathrm{c}$ ongestion a nd $\mathrm{p}$ rovided bette $\mathrm{r}$ performance gains (throughput and delay) than without congestion control.

\section{References}

1. Scott Shenker, Fundamental de sign issues for the fu ture internet, IEEE Journal on Selected Areas in Communications, 13(7) (1995) 1176-1188.

2. R. J. Gibbens and F. P. Kell y, Resource pricing and the evolution of con gestion con trol, ELSEVIER Automatica, 35(12) (1999) 1969-1985.

3. R. Jain, Congestion contro 1 in computer networks: issues and trends, IEEE Network, 4(3) (1990) 24-30.

4. Shujuan Wang and Mangui Liang, A credibility-based congestion control method, in Proc. Wicom (IEEE, Beijing, 2009).

5. Van Jacobson, Congestion avoidance and control, in Proc. SIGCOMM (ACM, NY, 1988), pp. 157-187. 
6. W. Prue, and J. Poste 1, So mething a host could do with source quen ch, RFC-1016, (N etwork Workin g Group, 1987).

7. U. Mukherii, A schedule-based approach for flow-control in data communication $\mathrm{n}$ etworks, Ph.d. Thesis, (Massachusetts Institute of Technology, 1986).

8. K. Ramakrishnan and R. Jain, A binary feedback scheme for congestion avoidan ce in co mputer networks, ACM Trans. on Computer Systems, 18(2) (1990) 158-181.

9. D. Comer and R. Yavatkar, A rate-based congestion avoidance and control sche me for packet $\mathrm{s}$ witched networks, in Proc. ICDCS, (IEEE, 1990), pp. 390-397.

10. A. Bharathan and J. McNair, An OPNET modeler study of the visa mechanism for $\mathrm{m}$ ulti-network auth entication, in Proc. OPNETWORK, (Washington, D.C., 2003).

11. S. Low and D. E. L apsley, Op timization fl ow control I: basic algorithm and conv ergence, IEEE Trans. Networking, 7(6) (1999) 861-874. 